\title{
La COVID-19 en el periodismo: un impacto ambivalente
}

The COVID-19 outbreak in journalism: an ambivalent incidence

Casero-Ripollés, Andreu

Universitat Jaume I de Castelló (UJ)

casero@uji.es

Forma de citar este artículo:

Casero-Ripollés, A. (2020). "La COVID-19 en el periodismo: un impacto ambivalente", RAEIC, Revista de la Asociación Española de Investigación de la Comunicación, vol. 7, núm. 14, 2-26. https://doi.org/10.24137/raeic.7.14.1

\section{Resumen:}

El brote de COVID-19 es un hecho altamente disruptivo para nuestra sociedad. Sus consecuencias han afectado a diferentes dominios sociales. Nuestro objetivo es analizar su impacto en el periodismo de forma panorámica y comprensiva. Pretendemos identificar las principales alteraciones y cambios que ha provocado la irrupción del Coronavirus. La metodología se basa en la técnica del análisis cualitativo de datos secundarios tomando con referencia el caso de España durante el primer período de la pandemia. Los resultados permiten identificar efectos positivos y negativos en cinco ámbitos: consumo de noticias, modelo de negocio, condiciones laborales, desinformación y relaciones con el ámbito político. Los hallazgos revelan que la incidencia de esta crisis sanitaria sobre el periodismo es ambivalente.

RAEIC, Revista de la Asociación Española de Investigación de la Comunicación vol. 7, núm. 14 (2020), 2-26 
Palabras clave: COVID-19, Coronavirus, periodismo, medios de comunicación, sistema mediático, modelo de negocio.

\begin{abstract}
:
The COVID-19 outbreak is a highly disruptive event in our society. Its consequences have affected different social domains. Our objective is to analyse its impact on journalism in a panoramic and comprehensive way. We intend to identify the main alterations and changes that the Coronavirus has caused. The methodology is based on the qualitative analysis of secondary data, taking as a reference the case of Spain during the first period of the pandemic. The results allow identifying positive and negative effects in five areas: news consumption, business model, working conditions, disinformation and relations with political actors. These findings reveal that the incidence of this health crisis in journalism is ambivalent.
\end{abstract}

Palabras clave: COVID-19, Coronavirus, journalism, media, media system, business models.

\title{
1. INTRODUCCIÓN
}

En 1987 el grupo musical REM popularizó una canción titulada "Es el fin del mundo tal como lo conocemos". Una banda sonora que podría ser aplicable a la irrupción de la COVID-19 en nuestra sociedad. Aparecida, inicialmente, en China a finales de 2019 y generalizada en Europa y el resto del mundo a partir de marzo de 2020, el brote de esta pandemia se configuró como un hecho altamente disruptivo. No sólo por su alta letalidad, al provocar 375.000 muertos y 6,1 millones de contagios en todo el mundo hasta principios de junio de 2020, sino por su capacidad de trastocar la totalidad de esferas de nuestra sociedad. De hecho, el Coronavirus se convirtió en un megaacontecimiento con potencial para generar consecuencias en diferentes dominios sociales, entre ellos el periodismo. Hasta el punto de concitar un amplio consenso alrededor de la idea que podría poner fin al mundo en el que habíamos vivido hasta 
ahora y provocar cambios sociales radicales, incrementando la incertidumbre y la fragilidad (Zizek, 2020).

El objetivo de este artículo es ofrecer una primera aproximación panorámica y comprensiva al impacto de la COVID-19 en uno de los principales dominios de nuestra sociedad: el periodismo. Con ello, pretendemos identificar las principales alteraciones y cambios que ha provocado la irrupción de esta pandemia en los procesos y dinámicas de funcionamiento del sector. De esta forma, se presentará un diagnóstico inicial sobre sus posibles efectos, que deberá ser contrastado en el futuro con nuevos análisis a medio y largo plazo.

Para ello, se usa la técnica del análisis cualitativo de datos secundarios procedentes de encuestas, estudios de audiencia y datos económicos sobre las empresas periodísticas. Como marco teórico interpretativo se recurre al rol social del periodismo, la comunicación política y la economía política de la comunicación. Se toma como marco geográfico el caso de España y como referencia temporal la primera etapa tras la irrupción de la pandemia en ese país (desde mediados de marzo a mediados de mayo de 2020) que coincide con el período de confinamiento de la población. Para articular el análisis se definen cinco ámbitos dentro de los cuáles se examina el impacto inicial de la COVID-19. Estos son los siguientes: consumo de noticias, modelo de negocio, condiciones laborales, desinformación y relaciones con el ámbito político.

\section{IMPACTO EN EL CONSUMO DE NOTICIAS}

La emergencia sanitaria provocada por el brote de la COVID-19 generó un fuerte aumento del consumo de noticias. La necesidad de obtener información para obtener conocimientos sobre la pandemia, para reducir la ansiedad y para poder orientarse ante la situación estimuló un incremento a nivel mundial de la demanda de información, tanto en los medios de comunicación, convencionales y digitales, como en las páginas web. De esta forma, la información periodística se convirtió en un producto dotado de un elevado valor social, revirtiendo la tendencia que, en los últimos tiempos, evidenciaba su pérdida de relevancia (Casero-Ripollés, 2014). 
Así, en Estados Unidos, según datos del Pew Research Center, el 92\% de los ciudadanos consumieron activamente noticias sobre el Coronavirus, registrando un aumento de 32 puntos porcentuales con motivo del brote. Sólo un 2\% declaró no buscar información sobre el virus. Por plataformas, el $96 \%$ de los estadounidenses se informaron sobre la COVID-19 a través de la televisión nacional en abierto y la televisión por cable. El 93\% optó por los medios impresos, el 94\% recurrió a páginas web o aplicaciones y, finalmente, el $87 \%$ acudió a las redes sociales. En España, el consumo de información durante los primeros días tras el confinamiento presentó cifras similares. Así, según datos de Havas Media, el 85\% de los ciudadanos utilizó la televisión para informarse sobre la pandemia. Un 54\% recurrió a la prensa digital mientras un 13\% optó por medios impresos. Finalmente, el $41 \%$ se informó a través de Internet y un 38\% mediante redes sociales. Resulta significativo indicar que sólo el $1 \%$ de los españoles declaró no buscar activamente información sobre el virus.

Estos datos evidencian dos tendencias interesantes. Por un lado, el pleno establecimiento de un sistema híbrido de medios en el que conviven medios tradicionales y medios digitales (Chadwick, 2017). En segundo lugar, la institución de una dinámica de complementariedad en el consumo de diferentes medios simultáneamente (Dutta-Bergman, 2004). Más que generar una sustitución de los viejos medios por parte de los nuevos, la COVID-19, ante la elevada demanda informativa, ha propiciado que los ciudadanos recurran a diversos soportes y canales mediáticos para obtener datos sobre la pandemia. Así, de forma complementaria, han buscado enriquecer su conocimiento del tema intentando combinar varios medios, obteniendo la mejor gratificación en términos informativos de cada uno de ellos.

Otra de las principales tendencias detectadas en el brote de Coronavirus fue el resurgimiento de los medios tradicionales frente a los digitales (Casero-Ripollés, 2020). Los mayores incrementos y porcentajes de consumo de noticias se focalizaron en estos medios, particularmente en la televisión. En un contexto marcado por el riesgo y la complejidad, el público optó por fuentes informativas establecidas, fiables y con una 
trayectoria consolidada (Nelson, 2020). De esta forma, los medios tradicionales se situaron en el centro del sistema comunicativo superando claramente a las redes sociales, las aplicaciones móviles o las páginas web como espacio preferente dónde informarse. Con ello, recuperaron parte de la autoridad periodística que habían perdido a consecuencia de la crisis de relevancia e identidad experimentada por estos medios durante la última década (Carlson, 2017).

En términos de datos de audiencia, en televisión, se produjo un incremento del $60 \%$ de la audiencia en Estados Unidos, según datos de Nielsen. Los informativos nocturnos de las cadenas generalistas en abierto crecieron un $42 \%$ respecto al mismo período del año anterior y las noticias por cable experimentaron una subida de un $92 \%$ en su audiencia en relación a inicios de 2020. Por su parte, en España, el consumo de televisión se incrementó un 37,8\% entre la primera y la segunda quincena de marzo de 2020, coincidiendo con el agravamiento de la situación sanitaria (Barlovento, 2020). Esto supuso un aumento de 88 minutos diarios por persona de consumo televisivo. Como resultado, el mes marzo de 2020 se registraron 284 minutos por persona y día de consumo de televisión, llegando incluso a 344 minutos por persona el domingo 15 de marzo de 2020. Se trata de los datos más elevados desde 1992, año en que empezaron a medir las audiencias televisivas en España.

Asimismo, la situación de confinamiento generó otro fenómeno relevante en el consumo de noticias y de medios: el desplazamiento de la franja de máxima audiencia desde el prime time al day time. Es decir, los datos indican que el horario preferente de consumo televisivo pasó de estar situado por la noche, a partir de las $22 \mathrm{~h}$., a ubicarse por las mañanas, entre las $9 \mathrm{~h}$. y las $14 \mathrm{~h}$. El incremento de audiencia en esta última franja en España durante el inicio del brote de Coronavirus fue del 64,5\% (Barlovento, 2020). En cambio, el prime time, más vinculado al entretenimiento, creció un 21,1\%. Esta tendencia no fue exclusiva de España, sino que también se detectó en otros países. Así, en Estados Unidos el day time creció entre un 39\% más con la irrupción de la crisis sanitaria, mientras el prime time retrocedió un 5\% (Weissbrot, 2020). Dos motivos explican este cambio. En primer lugar, a causa del confinamiento, creció la disponibilidad de tiempo de la ciudadanía para consumir noticias fuera de las franjas 
horarias en las que habitualmente las personas se encontraban fuera de casa desarrollando su trabajo. Incluso, gracias a la flexibilidad del teletrabajo, la necesidad de información causó el avance del consumo de noticias televisivas a la mañana. En segundo lugar, la vinculación del prime time con el entretenimiento y del day time con la información, como ingrediente clave para empezar el día, favoreció a este último en un contexto de alta demanda de noticias.

Por su parte, el incremento del tiempo de consumo de prensa digital en España durante las semanas iniciales de la crisis del Coronavirus fue del 35\% (Gfk, 2020). El tiempo dedicado a las redes sociales aumentó un 45\%. Por medios, el tiempo dedicado a Facebook subió un $46 \%$, a Instagram un $34 \%$ y a Twitter un $23 \%$. Esta última red, incrementó, además, también el número de usuarios en un $21 \%$, mientras que Instagram creció un 3\% y Facebook no experimentó un aumento de usuarios durante la segunda quincena de marzo de 2020 (Gfk, 2020).

Finalmente, el aumento generalizado del consumo de noticias durante el brote del Coronavirus también generó la reconexión del público menos interesado y más alejado de la información (Casero-Ripollés, 2020; Barlovento, 2020). Los aumentos más significativos en el consumo se registraron, tanto en Estados Unidos como en España, en las personas más desvinculadas previamente de las noticias como los jóvenes, las personas con menores niveles de formación educativa y los usuarios esporádicos de información. La necesidad de orientación y de conocer la evolución de la situación sanitaria generó un incremento notable de los porcentajes de consumo de noticias de estos grupos. Esta reconexión, propiciada por la COVID-19, de los ciudadanos distanciados de la información tiene consecuencias positivas en términos democráticos. Así, las desigualdades entre los ciudadanos a la hora de acceder a las noticias se han reducido, favoreciendo una mayor igualdad con sus consiguientes beneficios sociales y democráticos (Casero-Ripollés, 2020).

\section{IMPACTO EN EL MODELO DE NEGOCIO}

El aumento de consumo de noticias registrado a partir del inicio de la pandemia en España no vino acompañado de un incremento de los ingresos publicitarios de los 
medios. Al contrario, éstos se redujeron notablemente. Las caídas fueron generalizadas. Así, según datos de Infoadex, la reducción global del mercado publicitario español entre el primer trimestre de 2019 y el mismo período de 2020 fue del 10,2\%. En total, las pérdidas ascendieron a 140,6 millones de euros. Entre los medios de comunicación, el mayor descenso lo registraron los diarios que experimentaron una bajada del 26,3\%, equivalente a una pérdida de 24,9 millones de euros. La radio vio como sus ganancias publicitarias caían un $17,7 \%$, equivalentes a 20,3 millones de euros. Por su parte, la televisión bajó un 11,7\%, dejando de ingresar 58,5 millones de euros. Entre estos tres medios, acumularon un $73,75 \%$ del total de las pérdidas publicitarias derivadas de la COVID-19.

Estos datos ponen de manifiesto que, pese a la explosión del consumo de noticias, los ingresos de publicidad se han contraído fuertemente. Las explicaciones a esta paradoja pueden ser varias. En primer lugar, la reducción de la inversión de las marcas se debe, en parte, a la caída generalizada de ventas, derivada de la paralización económica impuesta por el confinamiento. Ante el cierre de establecimientos considerados no esenciales, decretado por el estado de alarma, la publicidad se frenó. Los sectores que mayor reducción de inversión publicitaria experimentaron fueron los viajes, la automoción y los deportes, que tradicionalmente eran quiénes destinaban más recursos económicos a anunciarse. Por otra parte, el desplazamiento de un porcentaje importante de la población hacia la compra online, cifrado en un 25\% (Fernández, 2020), puede generar nuevos hábitos de consumo que impacten en las inversiones publicitarias. En caso que esta crisis consolide este tránsito hacia el consumo online, los medios tradicionales pueden ver como en el futuro se reducen más sus ingresos publicitarios, dado que los anunciantes es probable que, en ese escenario, se orienten hacia los medios y plataformas digitales con mayor intensidad.

En segundo lugar, se ha reproducido una dinámica similar a la generada tras la crisis financiera mundial de 2007. Esta recesión eliminó unos 60.500 millones de dólares del mercado publicitario en todo el mundo (Fernández, 2020). Ante las dificultades económicas asociadas a la COVID-19 para las empresas, la inversión publicitaria ha sido una de las primeras partidas en reducirse o congelarse en muchas empresas y 
compañías. En Estados Unidos, un $56 \%$ de las marcas esperaban caídas en sus ventas durante el resto de 2020 (WARC, 2020). Como consecuencia de ello, un $81 \%$ de los anunciantes decidieron reducir su presupuesto para publicidad, un porcentaje que se sitúa en el $65 \%$ en el caso específico de la televisión tradicional. Asimismo, un $44 \%$ de los directores de marketing y comunicación en España prevén que el gasto publicitario se reducirá un $30 \%$ a lo largo de 2020 y un 24,1\% espera una bajada del 20\% (Good Rebels, 2020). Por su parte, el Gobierno de España prevé un descenso del Producto Interior Bruto (PIB) del 9,2\% a causa de la crisis derivada del Coronavirus. Estos datos permiten pronosticar que la contracción de la inversión publicitaria no desaparecerá con la vuelta a la nueva normalidad tras el fin del confinamiento. De hecho, la inversión publicitaria se contrae un 5\% por cada descenso de un punto del PIB (Picard, 2009). Es probable que, a causa del impacto de la crisis de la COVID-19 sobre la economía, los medios sufran, a corto y medio plazo, el impacto negativo sobre sus finanzas del descenso de la inversión publicitaria, debilitando notablemente su posición económica.

Junto a la reducción de ingresos publicitarios, el brote de Coronavirus también ha afectado a otro componente clave del modelo de negocio: la venta del producto periodístico. La emergencia sanitaria ha perjudicado notablemente a la venta de diarios en papel en los quioscos. Se estima que en España la caída de ventas impresas se situó entre el $80 \%$ y el $90 \%$ en los primeros días del confinamiento (Cano, 2020).

Antes de la irrupción de esta crisis, los medios se hallaban al inicio del proceso de transformación basado en la implantación de fórmulas de pago para el acceso en línea a sus contenidos. A finales de octubre de 2019, El Mundo fue el primer diario generalista de ámbito estatal en implantar un modelo freemium, con acceso gratuito a la última hora y mediante suscripción en el resto. Otros periódicos relevantes, como $A B C, L a$ Vanguardia o El País habían anunciado sus planes para implantar mecanismos de pago en sus versiones digitales. Sin embargo, ante la llegada de la COVID-19 estos medios, excepto El Mundo, optaron por paralizar sus planes y ofrecer toda la cobertura sobre el virus de forma gratuita en defensa del interés general. 
Pese a ello, el elevado consumo de noticias generado por el brote de Coronavirus, ha comportado un efecto importante: el incremento de las subscripciones de pago a los diarios digitales. En Europa, han aumentado un 267\%, mientras que en Estados Unidos la subida ha sido del 63\% (Cerezo, 2020). Estos datos parecen abrir la vía para superar el techo de lectores dispuestos a pagar por acceder a las noticias digitales que no lograba superar el 10\%-20\% del total. De hecho, recientemente una encuesta a nivel mundial cifraba ese porcentaje en un 16\% (World Economic Forum, 2020). Asimismo, los medios digitales que apuestan por ofrecer acceso gratuito a sus contenidos también se han beneficiado de este contexto de mayor predisposición al pago. Así, eldiario.es, tras poner en marcha una campaña, logró captar 9.000 nuevos socios, llegando a los 47.000 (Cerezo, 2020).

El reto del periodismo será mantener la voluntad hacia el pago o el apoyo económico de los lectores que ha generado la necesidad de información sobre la COVID-19 cuando finalice esta crisis. La emergencia sanitaria ha devuelto el valor de cambio que las noticias habían perdido en los últimos años (Casero-Ripollés, 2014). El brote de Coronavirus ha demostrado el camino a los medios para recuperar el valor de las noticias: apostar por una información de calidad y relevante para la vida de la ciudadanía. Los medios deben aprovechar la salida de este momento excepcional para implantar sus fórmulas de pago aprovechando la percepción ciudadana de la necesidad de noticias en el complejo mundo actual. Esto hace prever un incremento del número de medios que establezcan un pago por acceso a contenidos informativos a corto plazo en el entorno digital. De producirse, la COVID-19 habrá acelerado el cambio en el modelo de negocio de la prensa en un doble sentido. Por un lado, habrá potenciado las versiones digitales frente a las impresas. Por otro, habrá contribuido a configurar dos alternativas en el escenario digital, claramente polarizadas: los medios de pago y los medios gratuitos. Ambas formulas van a protagonizar una interesante pugna durante próxima década, en términos empresariales, en el camino hacia el establecimiento del modelo de negocio digital para la prensa. 


\section{IMPACTO EN LAS EMPRESAS PERIODÍSTICAS Y EN LAS CONDICIONES LABORALES DE LOS PERIODISTAS}

La reducción de los ingresos publicitarios a causa del brote de Coronavirus unido a la inmadurez de los modelos de subscripción digital, todavía en una fase emergente de implantación en España, ha provocado un fuerte impacto en la economía de los medios periodísticos. Cuatro asociaciones de empresas editoras de prensa, que representan a 260 grupos editoriales españoles, estimaron que la crisis de la COVID-19 supondrá pérdidas de 250 millones de euros (APM, 2020). Por el momento, los primeros resultados financieros demuestran la incidencia negativa de esta emergencia sanitaria. Así, los ingresos de Vocento cayeron un 6,1\% en el primer trimestre del 2020, aunque en su área de prensa el descenso fue del 11,5\%. Por su parte, Unidad Editorial (Unedisa) perdió un $19,7 \%$ de sus ingresos en el mismo período.

Estos datos indican el difícil equilibrio entre la monetización y la prestación de un servicio público indispensable, ofreciendo información sobre la pandemia, como el proporcionado por los medios periodísticos. Así, el aumento de la demanda de información no se traduce necesariamente en un impacto positivo en la dimensión empresarial del periodismo. Los medios no han logrado aprovechar el incremento de consumo de noticias para lograr beneficios económicos, generando una paradoja de monetización ineficiente y una notable debilitación empresarial. Esto les ha llevado a solicitar ayudas públicas para corregir este tipo de desequilibrios generados por el mercado y para proteger su función clave a la hora de proveer noticias sobre acontecimientos relevantes para la sociedad, como la COVID-19.

La pérdida de ingresos económicos por parte de las empresas periodísticas a causa del Coronavirus ha afectado a las condiciones laborales de los periodistas. Así, una de las primeras consecuencias ha sido la generalización de expedientes de regulación de empleo temporal (ERTE). Según datos del Ministerio de Trabajo, en el sector de los servicios informativos, que engloba al periodismo, 2.435 personas se vieron afectadas por algún ERTE hasta abril de 2020. Los grandes grupos editores de prensa en España (Prisa, Vocento, Prensa Ibérica, Unedisa, Godó, Henneo y Joly) se acogieron a esta 
fórmula, reduciendo la jornada y el sueldo a sus plantillas de periodistas entre un mínimo de un $11 \%$ y un máximo de un $50 \%$ en un período de entre tres y seis meses. Esto ha tenido un efecto directo en la producción de contenidos periodísticos que experimentó un retroceso del 14,2\% durante la fase inicial de la emergencia sanitaria en el conjunto del sector en España.

Asimismo, la reducción de los beneficios empresariales está también provocando un incremento de los despidos de periodistas, afectando negativamente a las condiciones laborales del sector. Antes de la llegada de la COVID-19, los datos de la Encuesta de Población Activa (EPA) señalaban el nivel de paro más bajo de la última década entre los periodistas en España. En cambio, los efectos de la pandemia han situado la cifra en 24.600 personas durante el primer trimestre de 2020, poniéndose en un nivel similar a los datos del primer trimestre de 2008, que marcaron el inicio de la crisis financiera que ha afectado intensamente al periodismo durante la última década. Por otra parte, en Estados Unidos se estima que la reducción de empleos en los medios a causa del Coronavirus se incrementará un 35\% respecto al año anterior. Con datos de principios de abril de 2020, el número de personas despedidas, suspendidas de empleo o afectadas por reducciones de salario era de 36.000 en total (Tracy, 2020). Un escenario que pone encima de la mesa el hecho que la pandemia pueda provocar un proceso de destrucción de empleo a nivel internacional. Algo que resultaría altamente perjudicial para los periodistas en términos laborales.

Por otra parte, otro de los efectos del confinamiento decretado por el estado de alarma ante el brote de la COVID-19 sobre las condiciones laborales de los periodistas ha sido el incremento del teletrabajo en el sector periodístico. Antes de la crisis del Coronavirus sólo un $19,6 \%$ de los periodistas afirmaban trabajar desde casa (LeanFactor, 2020). Sin embargo, la emergencia sanitaria ha vaciado las redacciones y ha activado modalidades de producción de información y de coordinación editorial a distancia de forma generalizada. En este sentido, se han potenciado los modelos organizativos en red y el mayor peso de lo digital en las estructuras empresariales. 
Varias empresas tecnológicas, como Facebook o Google, notificaron a sus empleados que trabajarían desde casa hasta principios de 2021. Por su parte, Twitter afirmó que permitiría el teletrabajo de forma permanente para algunos de sus perfiles profesionales incluso después de la pandemia. Por su parte, el editor de The New York Times, A. G. Sulzberger, anunció que hasta septiembre de 2020 no se volvería la redacción física y avanzó que había empezado a diseñar una visión a largo plazo para el trabajo a distancia a partir de lo aprendido con la experiencia de la COVID-19. Todo ello, indica que esta emergencia sanitaria ha acelerado el proceso de transformación digital de las organizaciones mediáticas y la descentralización del trabajo periodístico, que probablemente será cada vez menos dependiente de las redacciones físicas. En esta línea es probable que se incremente la flexibilidad laboral dentro del sector y que, incluso, emerjan nuevos modelos de relación contractual entre los periodistas y las empresas mediáticas. Igualmente, cabe esperar un incremento del protagonismo aún mayor de las tecnologías digitales en los procesos de producción de noticias y el aumento de la descentralización y la deslocalización. Alrededor del $40 \%$ de los periodistas españoles afirmaban que estas serán las consecuencias más probables de la COVID-19 para el sector según una encuesta (LeanFactor, 2020). Ambas fomentarán el avance de la mediatización profunda en el marco de la cuál lo digital se está intrincando de forma indisoluble con el periodismo, configurándose como la principal, y casi única, infraestructura que permite el funcionamiento del sector (Hepp, 2020).

El incremento de la flexibilidad y del teletrabajo puede comportar también amenazas para las condiciones laborales de los periodistas. En primer lugar, supondrá la necesidad de una mayor inversión tecnológica para las empresas periodísticas en un contexto en el que sus recursos económicos son escasos. En la crisis del Coronavirus sólo un 44,6\% de los periodistas españoles confirmó que su compañía le había dotado del equipamiento tecnológico necesario para teletrabajar con garantías (LeanFactor, 2020). Además, teniendo en cuenta el escenario de debilidad empresarial y de ERTE generalizados provocado por la COVID-19, no hay que descartar que estas nuevas dinámicas impliquen un adelgazamiento de las plantillas de los medios o un aumento de la precariedad en el sector. La aparición de nuevas formas de relaciones contractuales 
puede comportar un deterioro de los términos laborales para los profesionales del sector, con el consiguiente incremento de la inseguridad y la inestabilidad.

El teletrabajo y la alta demanda informativa ha comportado que los medios plantearan la puesta en marcha de nuevos formatos periodísticos en su cobertura de la COVID-19 (Casero-Ripollés, Marcos-García y Alonso-Muñoz, 2020). Los medios se esforzaron no sólo en producir noticias, sino también en generar nuevos productos informativos, como boletines digitales (newsletters), pódcast o infografías (Costa-Sánchez y López-García, 2020). Asimismo, ante la proliferación de noticias falsas, también potenciaron la verificación de datos y la lucha contra la desinformación. De esta manera, aportaron un valor añadido a la información periodística sobre el Coronavirus. Esta crisis ha demostrado que estos nuevos productos también contribuyen a potenciar la calidad informativa y la conexión con el público.

Por último, la COVID-19 ha afectado a las condiciones laborales de los periodistas desde el punto de vista sanitario. Al informar en primera línea sobre el virus, los profesionales del periodismo han puesto en riesgo su propia seguridad. Su trabajo les ha puesto, en muchos casos, en contacto directo con el Coronavirus. Esta situación ha supuesto peligros tanto físicos, por la posibilidad de contagiarse al cubrir la actualidad relacionada con la emergencia sanitaria, como psicológicos, al estar de manera diaria enfrentándose a las consecuencias de la pandemia. La presión por tener que informar sobre una enfermedad grave ha podido causar ansiedad y traumas a los periodistas. En este contexto, tanto la red de Colegios Profesionales de Periodistas en España como la Asociación Española de Comunicación Científica, el Committee to Protect Journalists o la Federación Internacional de Periodistas han publicado recomendaciones para informar con seguridad y tratar de mitigar los efectos de esta crisis sanitaria sobre los profesionales del sector (Costa-Sánchez y López-García, 2020).

Este alto riesgo para su salud al informar sobre la COVID-19 ha puesto de manifiesto el elevado compromiso social de los periodistas. Ante una situación potencialmente peligrosa, además de compleja, han antepuesto los valores del servicio público y la ética profesional para permitir a los ciudadanos el acceso a la información, entendida como 
base del conocimiento social. Además, han priorizado el derecho a la información de la ciudadanía, redoblando su dedicación laboral para producir información sobre la pandemia. Un 69\% de los periodistas españoles afirmó haber trabajado más horas que en la situación previa a la emergencia sanitaria (PRGarage, 2020). Así, han vuelto a demostrar, ahora en un momento crítico, su lucha por la libertad de expresión y el derecho a la información que constituyen las bases de una sociedad democrática. Algo que pone en valor no sólo la importancia del periodismo para la democracia, sino también el compromiso de sus profesionales con su promoción y defensa.

\section{IMPACTO EN LA DESINFORMACIÓN Y LA CIRCULACIÓN DE NOTICIAS FALSAS}

La circulación de noticias falsas experimentó un fuerte crecimiento a causa de la COVID19. Según datos de CoronaVirusFacts Alliance, una iniciativa que agrupa a diversas organizaciones de verificación de datos de todo el mundo bajo el impulso de la International Fact-Checking Network auspiciada por el Poynter Institute, a principios de mayo de 2020 se habían detectado 4.895 noticias falsas relacionadas con esta pandemia en todo el mundo. En España la cifra ascendía 500 informaciones engañosas durante ese mismo período según Maldita.es. Estos datos han llevado a la Organización Mundial de la Salud (OMS) a calificar esta situación como una infodemia. Este neologismo hace referencia a un exceso de información, mucha de ella falsa o engañosa, que impide a la ciudadanía acceder a las fuentes de información fiables sobre un tema.

La magnitud de este fenómeno en relación a la COVID-19 ha provocado la reacción de diversas instituciones. Así, la ONU ha impulsado a nivel mundial la iniciativa Verificado para hacer frente a la desinformación brindando información precisa y confiable. Por su parte, la OMS ha lanzado el proyecto EPI-WIN para desmentir los principales bulos sobre la pandemia. Asimismo, el Poynter Institute ha promovido la iniciativa CoronaVirusFacts Alliance para agrupar más de un centenar de organizaciones de verificación de datos de todo el mundo para hacer frente a la circulación de falsedades sobre el virus mediante el contraste de información. Incluso, la infodemia ha avivado el debate sobre cómo frenar judicialmente la difusión de noticias falsas en España. Por un lado, algunos han defendido esta idea con el argumento que el derecho a la información está 
fundamentado en la transmisión de hechos contrastados y que la difusión de mentiras acarrea responsabilidades judiciales (Carrillo, 1998). Por otro lado, se ha advertido que la persecución judicial de los bulos puede ser una excusa para restringir nuestras libertades y justificar y legitimar la implantación de medios de control de los ciudadanos poco compatibles con la democracia (Zizek, 2020).

Los ejemplos de noticias falsas relacionadas con el Coronavirus han sido diversos. Desde que su aparición está causada por la tecnología 5G hasta que este virus es, en realidad, un arma biológica desplegada por China o Estados Unidos para extender su dominio mundial pasando por helicópteros que lanzaban productos químicos de forma indiscriminada por encima de las ciudades para erradicar la plaga o por una gran variedad de tratamientos y remedios. En términos generales, los bulos vinculados a la COVID-19 se pueden englobar en cuatro grandes bloques: las causas de la aparición del virus, la enfermedad en sí misma (síntomas, transmisión y consecuencias), los tratamientos y formas de curación y, finalmente, la intervención y actuación de los poderes públicos frente a esta crisis.

Las plataformas digitales han sido los canales principales a través de los cuáles han circulado las noticias falsas sobre la COVID-19. Las redes sociales han sido el soporte en el cual los ciudadanos han detectado más informaciones de este tipo (Casero-Ripollés, 2020; Scheufele y Krause, 2019). Asimismo, los servicios móviles de mensajería instantánea, entre los que destaca WhatsApp, han jugado un papel clave en la extensión de noticias engañosas sobre la pandemia (Salaverría et al., 2020). Tres causas han convertido a esta plataforma en uno de los principales focos de la infodemia. Primero, el fuerte incremento del uso de estas aplicaciones, cifrado en un $76 \%$ al inicio del confinamiento en España, según datos de Kantar Media. Segundo, el carácter personal de su empleo, ya que son familiares o amigos quiénes envían los mensajes, circunstancia que activa la credibilidad de los usuarios. Y, tercero, la dificultad de identificar el origen de este tipo de mensajes por las características de esta aplicación. Según los principales portales de verificación de datos, las solicitudes para comprobar la falsedad de informaciones que se difundieron por este servicio de mensajería se multiplicaron por 
seis y llegaron al millar de casos diarios. De hecho, el $80 \%$ de las noticias falsas sobre el Coronavirus que circularon en España provenían de WhatsApp (Tardáguila, 2020).

El exceso de información, propiciada por las facilidades que hoy las tecnologías digitales conceden a cualquier persona para elaborar y distribuir contenidos, fraudulentos o no, y la multiplicidad de canales por los cuales circulan están en la base de este fenómeno. A ello, hay que unir, en el caso de la COVID-19, un clima social de miedo, riesgo e inseguridad. En este contexto marcado por estados anímicos inestables emocionalmente, la sociedad es más vulnerable ante las noticias falsas. De hecho, puede generar estados de infornoma, una patología vinculada al estrés y la ansiedad generados ante la saturación de información (Casasús, 1995). La tentación de conocer informaciones ocultas o prohibidas, que nadie se atreve a contar y el poder quiere silenciar, y el carácter escandaloso o polémico de los mensajes actúa como reclamo para captar la atención del público y hacerlo caer en la desinformación. Con ello, la circulación de los bulos se acrecienta en tiempo de crisis, como en el caso de esta pandemia. De hecho, las noticias falsas tienen un 70\% más de probabilidades de ser compartidas por los usuarios en las redes sociales que las verdaderas (Vosoughi, Roy y Aral, 2018).

Junto a su capacidad para generar ansiedad y confusión entre la ciudadanía, la desinformación también comporta un peligro en términos democráticos. Las noticias falsas tienen una dimensión política puesto que uno de sus objetivos es desestabilizar a la sociedad y a las instituciones gubernamentales, generando confusión y ansiedad entre la ciudadanía (Waisbord, 2018). La extrema derecha y el populismo hacen frecuentemente un uso en términos políticos de la desinformación y son los principales instigadores de este fenómeno (Bennett y Livingston, 2018). La COVID-19, por su propia gravedad y centralidad social, se ha convertido en un momento clave para la puesta en práctica de estrategias de desinformación y manipulación por parte de la ultraderecha de forma generalizada, recurriendo a campañas digitales minuciosamente planificadas y al uso de bots o cuentas automatizadas que se hacen pasar por humanos. Este tipo de organizaciones políticas alentaron la circulación de bulos con dos objetivos. 
En primer lugar, para erosionar y desacreditar a las instituciones políticas y mediáticas. Así, buscaban generar desconfianza sobre la gestión de la crisis realizada por el Gobierno y transformarla en descontento entre la ciudadanía. En España, se divulgaron noticias falsas sobre los privilegios de miembros del Gobierno frente a la pandemia, como que se había reservado una planta de un hospital público para la familia del presidente o que, frente a la vivienda del vicepresidente y su pareja, la Ministra de Igualdad, se habían dispuesto dos UVI móviles. También se culpabilizó al Ejecutivo de ocultar el número real de fallecidos, divulgando unas imágenes falsas de ataúdes correspondientes a la tragedia de Lampedusa, dónde en 2013 murieron 368 inmigrantes, o directamente se le acusó de las muertes con el hashtag \#Gobierno asesino en las redes sociales. Por su parte, también se trató de desacreditar a los medios de comunicación no afines a la causa de la ultraderecha para generar desconfianza entorno a ellos. De esta forma, se aspiraba a desautorizar a los intermediarios periodísticos para que sus mensajes y noticias falsas circulasen sin filtros ni alteraciones y generasen un impacto directo en la ciudadanía.

El segundo objetivo estaba relacionado con la promoción de su agenda política. Recurriendo a la desinformación, buscaban escandalizar y captar la atención del público para promover los temas y propuestas de su programa político, situándolos en el centro del debate político. Así, tanto en España como en otros países europeos, la extrema derecha culpabilizó y estigmatizó a la comunidad china de la creación y propagación del Coronavirus, aspecto que concuerda con su rechazo hacia la inmigración. De esta forma, durante la COVID-19, las noticias falsas, además de sembrar el desconcierto, aspiraban a tener un impacto político y democrático, potenciando la desafección hacia las instituciones y los medios, impulsando la polarización y la radicalización de la ciudadanía y promocionando la agenda política de la ultraderecha en la esfera pública. Por ello, el impacto que la pandemia ha tenido en este frente se puede traducir, a corto y medio plazo, en una debilitación de la influencia social del periodismo y la política, propiciando consecuencias negativas para la democracia. 


\section{IMPACTO EN LAS RELACIONES ENTRE PERIODISTAS Y POLÍTICOS}

La relación entre periodistas y políticos constituye un elemento central para la construcción de la realidad social (Casero-Ripollés, y López Rabadán, 2016). Del resultado de esta interacción depende, en gran parte, la información que llega a los ciudadanos y cómo se da forma a las noticias. Esto afecta tanto a la agenda pública, a qué temas se sitúan en el centro de la atención pública, como al proceso de configuración de la opinión de la ciudadanía.

La COVID-19 ha tenido un notable impacto en las relaciones entre el periodismo y la política al ser un acontecimiento dotado de una gran centralidad social. Particularmente ha provocado una reactivación de las dinámicas de control de la información por parte de los actores políticos, principalmente del Gobierno (Casero-Ripollés, 2009; Méndez Nieto, León Gross y Paniagua Rojano, 2018). Así, intentaron imponer su preponderancia para condicionar a su favor la cobertura periodística de esta crisis sanitaria.

El elemento clave a la hora de potenciar las lógicas de control político de la información relacionada con el brote de Coronavirus han sido los gabinetes de comunicación. En un contexto atípico, a causa de la aplicación de la normativa del estado de alarma, de la limitación de movimientos y del confinamiento, estos actores operaron como elemento estratégico clave a la hora de imponer la dominación política sobre la actividad informativa de los medios. Estos intermediarios desarrollaron activamente su función de escudo (Casero-Ripollés y López Rabadán, 2016) para intentar orientar tanto la agenda temática vinculada a la COVID-19 como, especialmente, el enfoque, o frame, bajo el cuál era construido el relato periodístico sobre el virus.

El mecanismo utilizado por los gabinetes de comunicación en el inicio del brote de Coronavirus para imponer su preponderancia fueron las ruedas de prensa. Ante la obligatoriedad de realizarlas telemáticamente, para evitar contagios y mantener la distancia social, se implantó, en muchos casos, un formato caracterizado por el filtro previo. Para formular sus preguntas, los medios tenían que remitirlas previamente a los gabinetes que se encargaban de seleccionarlas y enunciarlas al actor político compareciente. Con ello, no sólo podían evitar las cuestiones incómodas o alejadas del 
relato que deseaban transmitir, sino que, además, los políticos ya conocían las preguntas previamente y podían diseñar estratégicamente sus respuestas. Además, los periodistas no podían repreguntar o pedir aclaraciones adicionales. En consecuencia, los actores políticos instituyeron un alto control sobre la información relacionada con el Coronavirus.

Entre quiénes recurrieron a esta práctica se encontraban partidos políticos, como el Partido Popular (PP) o Vox, e instituciones públicas, como el Gobierno de España. En este último caso, la Secretaría de Estado de Comunicación creó un grupo de WhatsApp dónde los periodistas debían formular sus preguntas para el presidente o los diferentes ministros. Posteriormente, desde este organismo se seleccionaban las preguntas y su responsable las formulaba, en nombre de los medios, a los políticos en las ruedas de prensa. Algo similar hacía el PP mediante su vicesecretario de Comunicación.

Este formato, vinculado a un alto control de la tarea informativa de los periodistas, se mantuvo durante la primera quincena tras la irrupción de la pandemia. Ante la reducción de su autonomía profesional, una parte de los periodistas protestaron. Un grupo de medios liderados por el diario El Mundo e integrado por $A B C$, La Razón, Ok Diario, Libertad Digital y Vozpópuli decidieron no participar en estas ruedas de prensa con preguntas filtradas. Por otra parte, diversos periodistas lanzaron el manifiesto "La libertad de preguntar". Esta presión logró un cambio sustantivo en el formato. A partir de principios de abril, las ruedas de prensa pasaron a realizarse por videoconferencia permitiendo a los periodistas formular preguntas en directo, previamente no comunicadas al gabinete de comunicación. Tanto el Gobierno de España como el PP adoptaron esta nueva modalidad. En cambio, Vox continuó manteniendo el modelo anterior sin variar su intervencionismo informativo.

Pese al éxito de la reacción de los periodistas ante esta modalidad de control político de las ruedas de prensa, su percepción es que su trabajo fue notablemente entorpecido, principalmente por intereses políticos durante la COVID-19. Así, según una encuesta realizada por PRGarage (2020), el $80 \%$ de los periodistas españoles consideraba que habían sido desinformados durante esta crisis sanitaria. Asimismo, los fotoperiodistas 
también denunciaron las trabas impuestas por el Gobierno a la hora de obtener imágenes sobre los efectos del virus, restringiendo su acceso a morgues y hospitales (García, 2020). En consecuencia, la COVID-19 ha reavivado los intentos de control político de la información periodística ante la relevancia de este acontecimiento desde el punto de vista de la opinión pública.

\section{CONCLUSIONES}

El análisis de los cinco ámbitos permite comprobar que la COVID-19 ha tenido un impacto considerable en el periodismo. Esta incidencia es ambivalente ya que presenta tanto efectos positivos como negativos que afectan a diferentes vertientes del sector.

Entre los primeros, destaca que el brote de Coronavirus ha conllevado un notable incremento del consumo de noticias. De esta forma, la información periodística se ha situado como un producto clave dotado de un elevado valor como mecanismo fundamental para conocer el alcance y evolución de la pandemia. En este marco, los medios de comunicación tradicionales, especialmente la televisión, han obtenido un gran protagonismo, consiguiendo una alta centralidad social. Esto, sin duda, supone un fortalecimiento del periodismo, y de su papel, en la sociedad actual. Asimismo, la COVID19 ha permitido que aquellos públicos más alejados de las noticias se reconecten con la información ante un acontecimiento de fuertemente disruptivo y de riesgo para la vida humana. Con ello, ha generado un efecto beneficioso en términos democráticos.

Entre el balance positivo también destaca que el Coronavirus ha supuesto un impulso al empleo de nuevos formatos y productos informativos, como la infografía o los boletines informativos. Con ello, se ha contribuido a mejorar la calidad periodística y a conectar con el público. Asimismo, la COVID-19 ha contribuido a acelerar la transformación digital de los medios, potenciando el teletrabajo y la organización en red incrementando la flexibilidad y adaptabilidad del sector. Finalmente, en este contexto, la pandemia ha incrementado las subscripciones digitales. Con ello, cabe prever que estimule el tránsito generalizado de los medios hacia fórmulas de pago en el entorno digital y que reduzca todavía más la importancia de la versión impresa de los diarios. 
Pese a estos motivos para el optimismo, la COVID-19 también ha comportado efectos que pueden condicionar negativamente la evolución del periodismo. Así, la parálisis de la economía ha provocado una fuerte reducción de la inversión publicitaria. Esta circunstancia ha resultado muy dañina para las empresas periodísticas que han visto como su modelo de negocio quedaba debilitado por la disminución de sus ingresos. Paradójicamente, en el momento que más importancia social adquiría el periodismo y que mayores cifras de consumo de noticias se registraban, mayor era la fragilidad económica que afectaba a los medios. Esta situación se ha traducido en un deterioro de las condiciones laborales de los periodistas. El Coronavirus ha traído al sector despidos, ERTE y precarización, afectando nocivamente al empleo periodístico. Algo que constituye una seria amenaza para garantizar la calidad de las noticias, en un momento en que son más necesarias que nunca.

Finalmente, la COVID-19 también ha provocado efectos perniciosos sobre la función democrática del periodismo. Por un lado, ha reactivado los mecanismos de control político de la información y del trabajo de los periodistas, especialmente mediante las ruedas de prensa con filtro previo. Con ello, la autonomía profesional del periodismo se vio limitada. Por otro, el brote de Coronavirus ha supuesto un extraordinario incremento de las noticias falsas hasta el punto de ser catalogado de infodemia. Esto ha generado alarma, confusión y miedo entre la ciudadanía, causando inestabilidad y desconfianza. Además, la crisis sanitaria ha sido utilizada por la extrema derecha para impulsar la desinformación con la finalidad de erosionar a las instituciones políticas y periodísticas y para promocionar su agenda política. Algo que comporta un serio peligro en términos democráticos.

En todo caso, este elenco de efectos positivos y negativos ponen de manifiesto el poder disruptivo de la COVID-19 sobre el periodismo. Nuestro objetivo ha sido presentar una primera aproximación panorámica y comprensiva de la incidencia de la pandemia que permite establecer un diagnóstico inicial. Sin embargo, será necesario analizar su evolución futura para calibrar su verdadero alcance y su influjo a la hora de transformar el sector. 


\section{FINANCIACIÓN}

Este artículo forma parte del proyecto de investigación CSO2017-88620-P, financiado por la Agencia Española de Investigación (AEI) del Gobierno de España dentro del Plan Nacional de I+D+i.

\section{REFERENCIAS BIBLIOGRÁFICAS}

APM (2020). Editores de prensa periódica cuantifican esta crisis en 250 millones de euros, con caídas publicitarias de casi el 80\%. 23 de marzo de 2020. Disponible en https://www.apmadrid.es/editores-de-prensa-periodica-cuantifican-esta-crisis-en-250millones-de-euros-con-caidas-publicitarias-de-casi-el-80/

Barlovento Comunicación (2020). Cambio de hábitos y preferencias de la ciudadanía española frente al televisor por la crisis del Coronavirus. Informe especial, marzo 2020. Disponible en https://www.barloventocomunicacion.es/wpcontent/uploads/2020/04/Informe-especial-coronavirus-MARZO-2020ACTUALIZADO.pdf

Cano, F. (2020). Sin quioscos ni distribución: la crisis del Coronavirus acelera la caída de la prensa en papel. El Español, 24 de marzo de 2020. Disponible en https://www.elespanol.com/invertia/medios/20200324/sin-quioscos-distribucioncrisis-coronavirus-acelera-prensa/476953410 0.html

Carlson, M. (2017). Journalistic authority: Legitimating news in the digital era. Nueva York: Columbia University Press.

Carrillo, M. (1998). El derecho a la información, entre la ley y la autorregulación. Parlamento y Constitución. Anuario, 2, 119-131.

Casasús, J. M. (1995). El infornoma. La Vanguardia, 9 de enero de 1995, p. 14. Casero-Ripolles, A. (2020). Impact of Covid-19 on the media system. Communicative and democratic consequences of news consumption during the outbreak. El profesional de la información, 29(2), e290223. 
Casero-Ripollés, A. (2014). La pérdida de valor de la información periodística: causas y consecuencias. Anuario ThinkEPI, 8, 256-259.

Casero Ripollés, A. (2009). El control político de la información periodística. Revista Latina de Comunicación Social, 64, 354-366.

Casero-Ripollés, A. y López Rabadán, P. (eds.) (2016). Periodistas y políticos en España. Barcelona: Editorial UOC.

Casero-Ripollés, A., Marcos-García, S., y Alonso-Muñoz, L. (2020). New Formats for Local Journalism in the Era of Social Media and Big Data: From Transmedia to Storytelling. En J. Vázquez-Herrero, S. Direito-Rebollal, A. Silva-Rodríguez, X. LópezGarcía (Eds.), Journalistic Metamorphosis (pp. 69-83). Cham: Springer.

Cerezo, P. (2020). El impacto de la pandemia en la prensa. Abril 2020. Disponible en http://evocaimagen.com/dosieres/dosier-evoca-09-medios-y-coronavirus.pdf

Costa-Sánchez, C. y López-García, X. (2020). Comunicación y crisis del coronavirus en España. Primeras lecciones. El profesional de la información, 29(3), e290304.

Dutta-Bergman, M. J. (2004). Complementarity in consumption of news types across traditional and new media. Journal of broadcasting \& electronic media, 48 (1), 41-60.

Fernández, S. (2020). El Covid-19 golpea los medios y viste a 2020 de recesión publicitaria. El publicista, 31 de marzo de 2020. Disponible en https://www.elpublicista.es/reportajes/covid19-golpea-medios-viste-2020-recesionpublicitaria

García, C. (2020). España pone un veto a la tragedia y restringe el acceso de los fotoperiodistas a morgues y hospitales. Vozpópuli, 4 de abril de 2020. Disponible en https://www.vozpopuli.com/espana/Espana-restringe-fotoperiodistas-hospitalesmorgues-coronavirus 0 1342666982.html 
Good Rebels (2020). 2a oleada I Barómetro Covid-19 y marketing en España. 7 abril de 2020. Disponible en https://www.asociacionmkt.es/wp-content/uploads/2020/04/IBaroi\%CC\%80metro-COVID-19-y-Marketing Good-Rebels-2\%C2\%AA-oleada-.pdf

Hepp, A. (2020). Deep Mediatization. Londres: Routledge.

LeanFactor (2020). Sólo el 5\% de los periodistas españoles podía disfrutar de trabajo flexible en casa u oficina antes de la pandemia. 14 de mayo de 2020. Disponible en https://leanfactor.net/solo-el-5-de-los-periodistas-espanoles-podia-disfrutar-detrabajo-flexible-casa-u-oficina-antes-de-la-pandemia/

Méndez Nieto, A., León Gross, T. y Paniagua Rojano, F. (2018). El peso de la influencia de los gobiernos en las informaciones de la prensa de calidad. Estudios sobre el Mensaje Periodístico, 24(1), 233-250.

Nelson, J. L. (2020). The enduring popularity of legacy journalism: An analysis of online audience data. Media and Communication, 8(2), 40-50.

Picard, R. G. (2001). Effects of recessions on advertising expenditures: An exploratory study of economic downturns in nine developed nations. The Journal of Media Economics, 14(1), 1-14.

PRGarage (2020). Casi el 80\% de los periodistas españoles cree que se está desinformando durante la crisis y un 70\% trabaja más que antes. 15 de abril de 2020. Disponible en http://prgarage.es/periodismo-espana-coronavirus/

Salaverría, R., Buslón, N., López-Pan, F., León, B., López-Goñi, I., y Erviti, M. C. (2020). Desinformación en tiempos de pandemia: tipología de los bulos sobre la Covid-19. EI profesional de la información (EPI), 29(3), e290315.

https://doi.org/10.3145/epi.2020.may.15

Scheufele, D. A., y Krause, N. M. (2019). Science audiences, misinformation, and fake news. Proceedings of the National Academy of Sciences, 116(16), 7662-7669. 
Tardáguila, C. (2020). The demand for COVID-19 facts on WhatsApp is skyrocketing.

Poynter, 26 de marzo de 2020. Disponible en https://www.poynter.org/fact-

checking/2020/the-demand-for-covid-19-facts-on-whatsapp-is-skyrocketing/

Tracy, M. (2020). News Media Outlets Have Been Ravaged by the Pandemic, The New York Times, 1 de mayo de 2020. Disponible en

https://www.nytimes.com/2020/04/10/business/media/news-media-coronavirusjobs.html

Varol, O., Ferrara, E., Davis, C. B., Menczer, F., y Flammini, A. (2017). Online HumanBot Interactions: Detection, Estimation, and Characterization. En Proceedings of the Eleventh International AAAI Conference on Web and Social Media (ICWSM 2017), 280289.

Vosoughi, S., Roy, D., y Aral, S. (2018). The spread of true and false news online. Science, 359(6380), 1146-1151.

Waisbord, S. (2018). Truth is what happens to news: On journalism, fake news, and post-truth, Journalism studies, 19(13), 1866-1878.

WARC (2020). Global Ad Trends: FMCG and COVID-19, Marzo de 2020. Disponible en https://www.warc.com/content/paywall/article/warc-data/global-ad-trends-fmcg-covid-19/132154

Weissbrot, A. (2020). Daytime Is Streaming Time: TV Viewing Habits In The Time Of COVID-19. Adexchanger, 9 de abril de 2020. Disponible en https://www.adexchanger.com/tv-and-video/daytime-is-streaming-time-tv-viewinghabits-in-the-time-of-covid-19/

World Economic Forum (2020). Understanding Value in Media: Perspectives from Consumers and Industry, Abril 2020. Disponible en https://www.weforum.org/reports/value-in-media\#report-nav

Zizek, S. (2020). Pandemia. La covid-19 estremece al mundo. Barcelona: Anagrama. 